\title{
Efficacy of serum procalcitonin to predict spontaneous preterm birth in women with threatened preterm labour: a prospective observational study
}

Guillaume Ducarme $^{1 *}$, François Desroys du Roure ${ }^{2}$, Aurélie Le Thuaut ${ }^{3}$, Joséphine Grange ${ }^{1}$, Mathilde Vital ${ }^{1}$ and Jérôme Dimet ${ }^{2}$

\begin{abstract}
Background: A hypothesis of preterm parturition is that the pathogenesis of spontaneous preterm birth (sPTB) may be associated with an inflammatory process. Based on this theory, we have hypothesized that an inflammatory biomarker, procalcitonin (PCT), may be a good predictive marker of sPTB at the admission for threatened preterm labour (TPL). The present study was aimed to investigate the association between serum PCT and sPTB in women with TPL and to evaluate whether PCT levels may predict SPTB in women with TPL within 7 or 14 days.

Methods: In a prospective observational laboratory-based study, women with singleton pregnancies, TPL between 24 and 36 weeks and intact membranes, were enrolled between January 2014 and June 2016. Participants received routine medical management of TPL (tocolysis with atosiban, antenatal corticosteroids, and biological tests at admission (C-reactive protein, white blood cell count, and PCT measured on electrochemiluminescence immunoassay)). The primary endpoint was SPTB before 37 weeks of gestation. The value of serum PCT levels to predict SPTB within 7 or 14 days were evaluated using receiver-operating curves (ROC) analysis.

Results: A total of 124 women were included in our study. PCT levels did not statistically differ between women with SPTB $(n=30,24.2 \%)$ and controls $(n=94)$ (median in $n g / m L$ [interquartile range]: 0.043 [0.02-0.07] compared to $0.042[0.02-0.13]$, respectively; $P=0.56)$. PCT levels did not also statistically differ between women with sPTB within 7 days $(n=7,5.6 \%)$ or 14 days $(n=12,9.7 \%)$ after testing and controls. Moreover, subgroup analysis revealed no difference among PCT levels at admission between 24 and 28 weeks, between 28 and 32 weeks and over 32 weeks, and controls. On the basis of the receiver-operating characteristic curve, the highest sensitivity and specificity corresponded to a PCT concentration of $0.038 \mathrm{ng} / \mathrm{mL}$, with poor predictive values for SPTB within 7 or 14 days.
\end{abstract}

Conclusion: Serum PCT was not relevant to predict SPTB within 7 or 14 days in women admitted with TPL between 24 and 36 weeks, and thus it is not a suitable biological marker to confirm the hypothesis of an inflammatory process associated with preterm parturition.

Trial registration: Clinicaltrials.gov (NCT01977079), Registered 24 October 2013.

Keywords: Procalcitonin, Spontaneous preterm birth, Threatened preterm labour

\footnotetext{
* Correspondence: g.ducarme@gmail.com

'Department of Obstetrics and Gynaecology, Centre Hospitalier

Departemental, La Roche sur Yon, France

Full list of author information is available at the end of the article
} 


\section{Background}

Spontaneous preterm birth (sPTB) before 37 weeks' gestation occurs in approximately $4.5 \%$ to $18 \%$ of pregnancies worldwide [1-3], still remains the leading cause of neonatal mortality and morbidity worldwide, causes over $70 \%$ of fetal death rates and approximately $50 \%$ of neonatal neural deficits [4], and has effects on survivors that may be lifelong [5]. An episode of threatened preterm labour (TPL) is a common cause of hospitalization during pregnancy with a frequency ranging from $9 \%$ to $24 \%$ [6-9]. Nevertheless, approximately $50 \%$ of these women with TPL will present SPTB [9]. The scale of the problem of prematurity, and the severity of its consequences, have spurred extensive research into potential causes and efficient predictors of $\operatorname{sPTB}[9,10]$. A hypothesis of preterm parturition is that the pathogenesis of $\mathrm{SPTB}$ may be associated with an inflammatory process [1114]. Romero et al. have described the preterm parturition syndrome, a heterogeneous condition with premature labour as the common endpoint. They proposed that SPTB may be a result of pathological activation of signals that subsequently initiate labour rather than it is a process that is abnormal only in its timing [14].

Procalcitonin (PCT) is a 116-amino acid peptide, which is a good predictive marker of an inflammatory process with rapidly increased serum levels in inflammation or sepsis $[15,16]$. Although serum PCT levels have been studied in pregnant women with preterm premature rupture of membranes (PPROM) [17, 18], only one publication with a small sample size $(n=53)$ has specifically evaluated PCT in women with preterm labour compared to healthy pregnant patients [19]. Based on these theories [11-14], we have hypothesized that an inflammatory biomarker may be a good predictive marker of sPTB at the admission for TPL. Thus, we aimed to evaluate the association between serum PCT levels and sPTB in women hospitalized with TPL between 24 and 36 weeks. The secondary objective was to evaluate whether serum PCT levels may predict SPTB within 7 or 14 days after testing.

\section{Methods}

\section{Study design, site, aims and sample size}

A prospective observational laboratory-based study took place from January 2014 to June 2016 at a tertiary care hospital with more than 2600 annual deliveries. Only one study had evaluated serum PCT concentrations in 53 women with preterm labour compared to 31 healthy pregnant women [19]. No study has specifically evaluated whether serum PCT levels may predict SPTB within 7 or 14 days in women hospitalized with TPL between 24 and 36 weeks. So, no sample size estimation has been done before the beginning of the study, and an interim analysis had been planned two years after the beginning of the study (with an estimation of 100-120 included women regarding our hospital data).

The aims were to evaluate the association between serum PCT levels and SPTB in women hospitalized with TPL between 24 and 36 weeks, and to evaluate whether serum PCT levels may predict SPTB within 7 or 14 days after testing.

\section{Characteristics of participants and description of methods} The study included pregnant women with a live singleton pregnancy, intact membranes, hospitalized with TPL between 24 and 36 weeks of gestation. Exclusion criteria were multiple gestations, known uterine malformation, cervical cerclage in situ, PPROM, suspected chorioamnionitis at the time of presentation, cervical dilatation of more than three centimetres, previous treatment with tocolysis within 7 days before inclusion, gestational hypertensive diseases, fetal growth restriction (defined as $<10$ th centile for gestational age on Hadlock curves [20, 21], known congenital anomaly, white blood cell (WBC) count> $15.0 \mathrm{G} / \mathrm{L}$ [22], C-reactive protein (CRP) > $10 \mathrm{mg} /$ L [23], and contra-indications for tocolysis, such as suspected intra-uterine infections or fetal distress.

TPL was defined as the presence of regular and painful uterine contractions that registered by cardiotocography (at least, 2 uterine contractions/10 min during $20 \mathrm{~min}$ ), intact membranes before 37 weeks and ultrasound cervical length $<25 \mathrm{~mm}$ [24-26], and which may result in preterm birth [27, 28]. Gestational age at delivery was determined by the crownrump length at a first-trimester ultrasound examination or by the date of last menstrual period and/or a second- or third-trimester ultrasound if the firsttrimester ultrasound was not performed [29]. Premature births, by definition, occur prior to 37 completed weeks of gestation, and was further categorised into extreme prematurity (less than 28 weeks of gestation), severe prematurity (28-31 weeks), and moderate prematurity (32-36 weeks) [30].

The technique for ultrasound cervical length measurement has been described in detail in prior reports [26, 31]. Ultrasound cervical length measurements were subjected to a quality assurance protocol. Each ultrasound examination included 3 transvaginal sonographic cervical length measurements, and the shortest measurement was recorded. Fundal pressure was not used to assess the shortest cervical length. When a cervical funnel was present, the cervical length below the funnel was recorded.

For all patients recruited in to this study, a full examination was conducted by the attending physician. We performed standardized medical management of TPL between 24 and 36 weeks of gestation with intact membranes (sterile speculum examination, digital examination, 
sonographic cervical length measurement, tocolysis with atosiban, and intramuscular betamethasone $2 \times 12 \mathrm{mg} /$ $24 \mathrm{~h}$ ), according to recommendations and international clinical standards [24]. Although all women with TPL should not be treated with antibiotics, antibiotics in women with TPL were used in cases of group B streptococcal colonization. The clinicians were blinded to the PCT results, and the study did not modify patient management.

Maternal sociodemographic characteristics, clinical characteristics at admission, information regarding pregnancy follow up and standard perinatal outcomes were collected prospectively by the midwife or obstetrician and paediatrician responsible for the delivery and the child. Other data were collected by a research assistant, independent of the local medical team, from a prospectively maintained database of women who were included in the study. In addition, we routinely measured newborns' umbilical arterial blood gases at birth. A paediatrician examined the newborn in all cases after delivery. Infants in need of close monitoring were transferred to the neonatal intensive care unit (NICU).

Blood samples on admission were collected in the polypropylene tubes were immediately centrifuged and the supernatant was then stored at $-35{ }^{\circ} \mathrm{C}$ until analysis. All analysis were done in the Department of Biology by the same biologist (FDR) and all PCT levels were measured in serum within $48 \mathrm{~h}$ after blood sampling via the immunoluminometric automatic analyser Cobas 6000 e601 (Roche Diagnostics International Ltd., Rotkreuz, Switzerland). The lower limit of detection of the assay was $0.02 \mathrm{ng} / \mathrm{mL}$ and the functional assay sensitivity was $0.06 \mathrm{ng} / \mathrm{mL}$ (Cobas 6000 e601; PCT package insert; Roche Diagnostics International Ltd). The assay sensitivity and inter- and intra-assay coefficients of variation (CVs) of the PCT kits, as reported by the manufacturers, are $4-10 \%$. WBC count was determined automatically with XE-2100 Automated Haematology System (Sysmex Corporation, Kobe, Japan). CRP was measured quantitatively by immunoturbidometry with the Cobas 6000 c501 system (Roche Diagnostics International Ltd., Rotkreuz, Switzerland). The lowest detection limit of CRP with this method is $0.3 \mathrm{mg} / \mathrm{L}$. In the study group, the cervicovaginal secretion was cultured for aerobic and anaerobic bacteria.

The endpoint was SPTB before 37 weeks of gestation. Women in the case group were defined as included women who were admitted with TPL between 24 and 36 weeks of gestation but presented ultimately sPTB before 37 weeks of gestation. Women in the control group were defined as included women who delivered at term ( $\geq 37$ weeks of gestation).

\section{Statistical analysis}

Demographic data were evaluated using descriptive statistics. Continuous data were described by their means \pm standard deviations and compared by t-tests (or MannWhitney tests when appropriate); categorical data were described by percentages and compared by chi-square tests (or Fisher exact tests when appropriate). Serum PCT levels were not normally distributed and therefore are reported as medians and interquartile intervals. Univariate analysis were used to compare serum PCT level at admission for TPL and gestational age at birth, and to compare PCT level at admission and admission-todelivery interval. Receiver operating characteristic (ROC) curves were generated to identify which cut-off of PCT value produced the best sensitivity to predict $\mathrm{SPTB}$ within 7 or 14 days after testing. STROBE guidelines/ methodology for a prospective observational study were adhered to. Statistical analyses were performed with Statistical Package for Social Sciences (SPSS) software (version 17.0, SPSS Inc., Chicago, IL, USA). A $p$-value of $<0.05$ was considered statistically significant.

\section{Results}

The study enrolled 124 patients during the study period (Fig. 1). The scheduled interim analysis showed that the magnitude of the between-group difference of serum PCT level was very small, and a sample size estimate of 7066 patients admitted with TPL should be included to show a significant difference on serum PCT levels with clinical relevance. So, the study was stopped because of negative results. Maternal and neonatal characteristics are presented in Table 1.

The mean age was $27.3 \pm 4.8$ years, and the mean gestational age at presentation was 31.7 weeks (range: $24.8-$ 34.6 weeks). The mean gestational age at birth was 38.0 \pm 2.2 weeks, and the mean interval between admission to delivery was $44.3 \pm 21.9$ days. Spontaneous preterm birth occurred in 30 women (24.2\%). There was no statistically difference between the two groups of women, with the exception of gestational age at birth $(p<0.001)$, the interval between admission to delivery $(\mathrm{p}<0.001)$, and birth weight of newborns $(\mathrm{p}<0.001)$. Specifically, no difference was observed between the two groups on WBC, CRP, Bishop score and sonographic measurement of cervical length at admission (Table 1).

Only one woman delivered within 48 h. Some 12 women $(9.7 \%)$ delivered within 14 days of presentation. We also found that 7 of 124 women (5.6\%) delivered before 7 days from the time of admission (delivery time interval $4.4 \pm 1.9$ days, gestational age at birth $33.8 \pm$ 1.2 weeks), whereas the remaining women delivered later (delivery time interval $46.7 \pm 20.2$ days, gestational age at birth $38.3 \pm 1.9$ weeks), with a statistically significant difference between gestational age at birth $(p<0.001)$. 


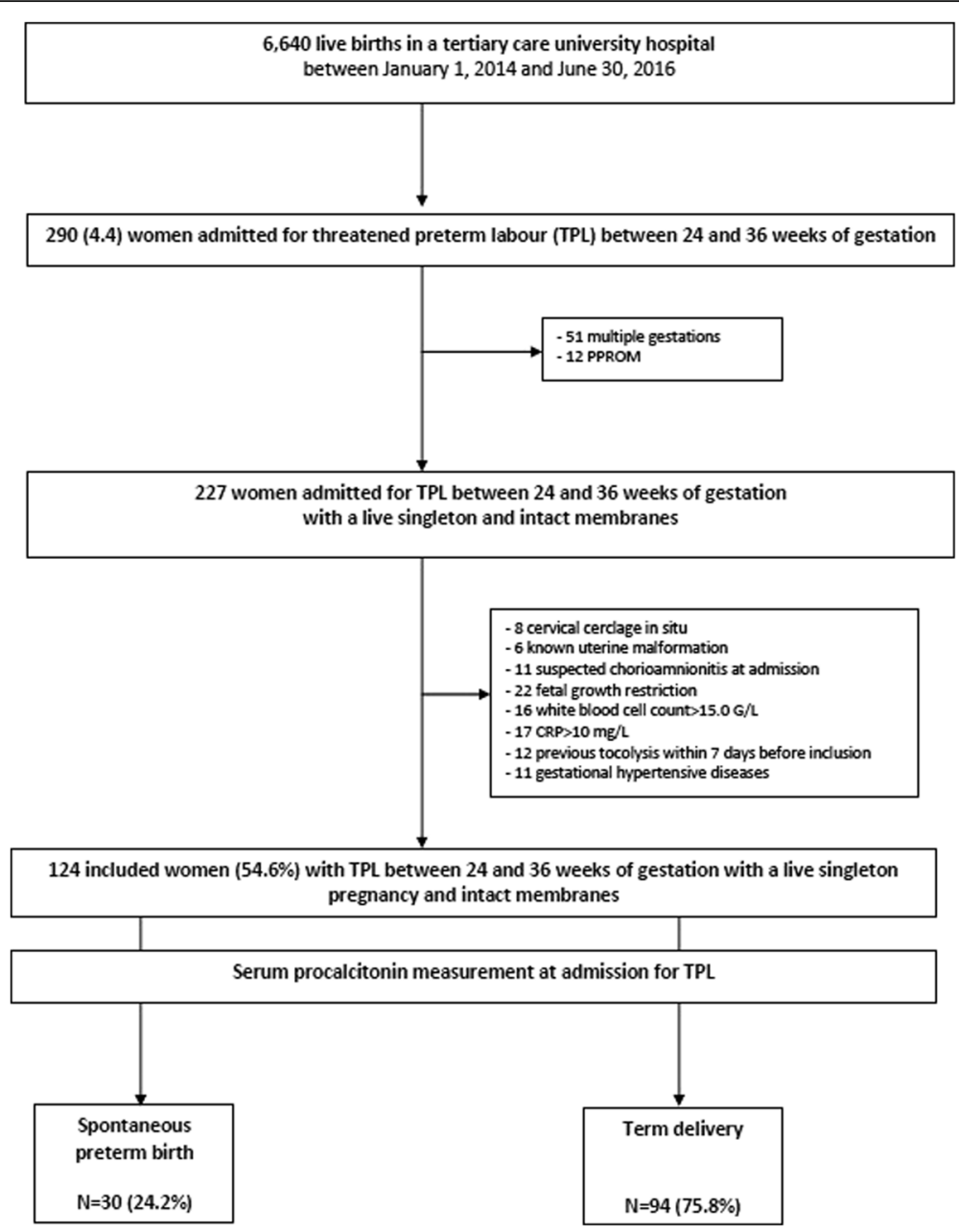

Fig. 1 Flowchart

Serum PCT levels were measurable in all samples. As shown in Table 1, serum PCT were not significantly different in women who delivered preterm (median $0.042 \mathrm{ng} / \mathrm{mL}$, interquartile range $0.034-0.054 \mathrm{ng} / \mathrm{mL}$ ) compared to women who delivered at term (median $0.039 \mathrm{ng} / \mathrm{mL}$, interquartile range $0.030-0.050 \mathrm{ng} / \mathrm{mL}$ ). Moreover, subgroup analysis revealed no significant difference among PCT levels at admission between 24 and 28 weeks, between 28 and 32 weeks, and over 32 weeks, and controls, respectively (Table 2). PCT levels did not also statistically differ between women who delivered within 7 days or 14 days after testing and the others (Table 2).

PCT levels were not correlated to Bishop score at admission or to other routine laboratory tests (WBC and CRP) at admission for TPL. The cut-off value was then determined by application of ROC curve analysis for PCT levels against SPTB and admission-to-delivery intervals $\leq 7$ and $\leq 14$ days. For all of them, the highest sensitivity and specificity corresponded to a PCT concentration of $0.038 \mathrm{ng} / \mathrm{mL}$, and the predictive values were generally poor (Table 3 ).

\section{Discussion}

Our prospective, observational, laboratory-based study found that PCT levels at admission for TPL between 24 and 36 weeks of gestation did not statistically differ between women with SPTB and term birth, and serum PCT have poor predictive values for $\mathrm{SPTB}$ and admission-to-delivery intervals $\leq 7$ and $\leq 14$ days. Moreover, subgroup analysis revealed no difference among PCT levels at admission between 24 and 28 weeks, between 28 and 32 weeks and over 32 weeks, and controls.

The principal strength of this study is the exclusion of all situations which may influence the initial evaluation of women with TPL at admission and the exclusion of all situations which may also influence perinatal outcome (gestational age at birth, admission-to-delivery interval, neonatal morbidity), as multiple gestation, known uterine malformation, cervical cerclage in situ, or 
Table 1 Maternal characteristics and maternal and neonatal outcomes according to gestational age at birth

\begin{tabular}{|c|c|c|c|}
\hline & $\begin{array}{l}\text { Term delivery } \\
n=94(75.8 \%)\end{array}$ & $\begin{array}{l}\text { Preterm delivery } \\
\mathrm{n}=30(24.2 \%)\end{array}$ & $p$-value \\
\hline \multicolumn{4}{|l|}{ Maternal characteristics } \\
\hline Maternal age (years) & $26.9 \pm 4.7$ & $28.5 \pm 5.0$ & 0.12 \\
\hline BMI before pregnancy $\left(\mathrm{kg} / \mathrm{m}^{2}\right)$ & $21.9 \pm 4.4$ & $21.3 \pm 3.2$ & 0.68 \\
\hline Nulliparity & $51(54.3)$ & $16(53.3)$ & 0.93 \\
\hline \multicolumn{4}{|l|}{ Variables at admission for TPL } \\
\hline Gestational age at sampling (weeks) & $32.5[30.1-33.1]$ & $32.5[31.1-33.4]$ & 0.48 \\
\hline Bishop score & $3.9 \pm 1.9$ & $4.7 \pm 1.9$ & 0.08 \\
\hline Cervical length (mm) & $19.6 \pm 5.6$ & $17.9 \pm 7.3$ & 0.20 \\
\hline$P C T^{\mathrm{a}}(\mathrm{ng} / \mathrm{mL})$ & $0.039[0.030-0.050]$ & $0.042[0.034-0.054]$ & 0.56 \\
\hline White blood cell count $\left(\times 10^{9} / L\right)$ & $11.0 \pm 2.2$ & $11.0 \pm 2.2$ & 0.91 \\
\hline C-reactive protein (mg/L) & $3.8 \pm 2.5$ & $3.6 \pm 2.3$ & 0.76 \\
\hline Positive cervicovaginal swab cultures & $5(5.4)$ & $5(17.2)$ & 0.06 \\
\hline \multicolumn{4}{|l|}{ Maternal outcome } \\
\hline Gestational age at delivery* (w) & $39.0 \pm 1.2$ & $35.0 \pm 1.7$ & $<0.001$ \\
\hline Interval between admission to delivery (days) & $51.6 \pm 18.1$ & $21.7 \pm 17.1$ & $<0.001$ \\
\hline Caesarean delivery & $1(1.1)$ & $3(10.0)$ & 0.04 \\
\hline \multicolumn{4}{|l|}{ Neonatal outcome } \\
\hline Birth weight (g) & $3068.3 \pm 392.4$ & $2381.2 \pm 422.7$ & $<0.001$ \\
\hline 5 min Apgar score (points) & $9.7 \pm 1.1$ & $9.4 \pm 1.9$ & 0.39 \\
\hline 5-min Apgar score $<7$ & $4(4.4)$ & $1(3.4)$ & 0.99 \\
\hline Transfer to NICU & $3(3.2)$ & $4(13.3)$ & 0.06 \\
\hline Neonatal death & 0 & 0 & - \\
\hline
\end{tabular}

TPL Threatened preterm labour

*Gestational age at sampling (weeks) is expressed as median [interquartile range]

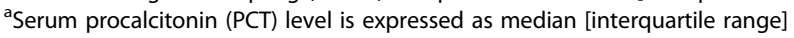

Continuous data are expressed as means \pm standard deviations; discrete data are expressed as $\mathrm{n}$ or $\mathrm{n}$ (\%). Student $\mathrm{t}$ test, $\mathrm{x} 2$ test, non-parametric Mann-Whitney test, and Fisher's exact test were used as appropriate. A p-value of 0.05 was considered significant

Table 2 Serum procalcitonin levels

\begin{tabular}{|c|c|c|c|c|}
\hline & $\begin{array}{l}\text { All patients } \\
(n=124)\end{array}$ & $\begin{array}{l}\text { Term delivery } \\
(n=94)\end{array}$ & $\begin{array}{l}\text { Preterm delivery } \\
(n=30)\end{array}$ & $p$-value \\
\hline $\mathrm{PCT}$ level at admission for $\mathrm{TPL}(\mathrm{ng} / \mathrm{mL})$ & $\begin{array}{l}0.040[0.031-0.050] \\
(n=124)\end{array}$ & $\begin{array}{l}0.039[0.030-0.050] \\
(\mathrm{n}=94)\end{array}$ & $\begin{array}{l}0.042[0.034-0.054] \\
(n=30)\end{array}$ & 0.56 \\
\hline \multicolumn{5}{|l|}{$\begin{array}{l}\text { PCT level according to gestational age } \\
\text { at admission }(\mathrm{ng} / \mathrm{mL})\end{array}$} \\
\hline Between 24 and 28 weeks & $\begin{array}{l}0.028[0.020-0.038] \\
(n=8)\end{array}$ & $\begin{array}{l}0.028[0.020-0.035] \\
(n=6)\end{array}$ & $\begin{array}{l}0.031[0.020-0.042] \\
(n=2)\end{array}$ & 0.99 \\
\hline Between 28 and 32 weeks & $\begin{array}{l}0.042[0.032-0.049] \\
(n=42)\end{array}$ & $\begin{array}{l}0.040[0.032-0.049] \\
(n=34)\end{array}$ & $\begin{array}{l}0.042[0.034-0.053] \\
(n=8)\end{array}$ & 0.66 \\
\hline$>$ or equal to 32 weeks & $\begin{array}{l}0.040[0.032-0.050] \\
(n=73)\end{array}$ & $\begin{array}{l}0.040[0.030-0.047] \\
(n=53)\end{array}$ & $\begin{array}{l}0.041[0.034-0.055] \\
(n=20)\end{array}$ & 0.65 \\
\hline \multicolumn{5}{|l|}{$\begin{array}{l}\mathrm{PCT} \text { level according to admission-to- } \\
\text { delivery interval }(\mathrm{ng} / \mathrm{mL})\end{array}$} \\
\hline$>7$ days & $\begin{array}{l}0.039[0.030-0.048] \\
(n=117)\end{array}$ & $\begin{array}{l}0.039[0.030-0.047] \\
(n=94)\end{array}$ & $\begin{array}{l}0.042[0.034-0.054] \\
(n=23)\end{array}$ & 0.76 \\
\hline$>14$ days & $\begin{array}{l}0.039[0.030-0.049] \\
(n=112)\end{array}$ & $\begin{array}{l}0.039[0.030-0.047] \\
(n=94)\end{array}$ & $\begin{array}{l}0.039[0.030-0.054] \\
(n=18)\end{array}$ & 0.97 \\
\hline
\end{tabular}


Table 3 The prognostic value of serum PCT determinations in the prediction of spontaneous preterm delivery and admission-todelivery interval

\begin{tabular}{|c|c|c|c|}
\hline \multirow[t]{2}{*}{$P C T \geq 0.038 \mathrm{ng} / \mathrm{mL}$} & \multicolumn{3}{|l|}{ Delivery } \\
\hline & $\leq 36$ weeks & Within 7 days & Within 14 days \\
\hline Sensitivity (\%) & $63.3[43.9-80.1]$ & $57.1[18.4-90.1]$ & $66.7[34.9-90.1]$ \\
\hline Specificity (\%) & $47.3[36.9-57.9]$ & $44.8[35.6-54.3]$ & $45.9[36.4-55.7]$ \\
\hline Positive predictive value (\%) & $27.9[17.7-40.1]$ & $5.9[1.6-14.4]$ & $11.8[5.2-21.9]$ \\
\hline Negative predictive value (\%) & $80.0[67.0-89.6]$ & 94.5 [84.9-98.9] & 92.7 [82.4-98.0] \\
\hline Likelihood ratio + & $1.20[0.86-1.68]$ & $1.04[0.53-2.01]$ & $1.23[0.80-1.91]$ \\
\hline Likelihood ratio - & $0.77[0.46-1.30]$ & $0.96[0.40-2.30]$ & $0.73[0.32-1.66]$ \\
\hline
\end{tabular}

PPROM. However, it is important to note that patients with any biological or clinical sign of infection and/or chorioamnionitis were excluded from the study, minimizing the interference of infectious mechanisms on the timing of birth. Preterm birth may occur in one of three circumstances: iatrogenic due to fetal or maternal requirement, sPTB with intact membranes, or PPROM [30]. Then, our strict inclusion and exclusion criteria allow us to evaluate serum PCT in a homogeneous group of women admitted for TPL with intact membranes and strength our results concerning PCT levels as a potential predictive factor of sPTB. Second, our rates of sPTB before 37 weeks $(24.2 \%)$ and spontaneous birth seven days following admission for TPL (5.6\%) were in accordance with other published study concerning TPL in France. Pinton et al. reported rates of delivery before 37 weeks and seven days following enrolment in a prospective study in Strasbourg, France, which were $28 \%$ and $10 \%$, respectively [32]. Third, we used a standardized measure of serum PCT in a prospective laboratory-based study with carefully characterized obstetric patients and prospectively maintained database of included women. This allowed a complete evaluation of serum PCT for women presented TPL. Four, our results concerning serum PCT levels at admission were consistent with other findings in the literature about PCT levels during normal pregnancy [33, 34]. Kucukgoz Gulec et al. evaluated PCT in 64 preeclamptic patients compared to 33 healthy pregnant patients. They reported a median PCT level at $0.040 \mathrm{ng} / \mathrm{mL}$ (interquartile range $0.002-$ $0.075)$ at $35.1 \pm 2.6$ weeks of gestation in normal pregnancies [34].

\section{Limitations of the study}

Our study has some limitations. First, that the study was underpowered to show a significant difference on serum PCT levels with clinical relevance. The decision to stop the study was based on the very small magnitude of the between-group difference without clinical relevance and a sample size estimate of 7066 patients with TPL who should be included to show a significance difference on serum PCT levels. Second, we only studied PCT levels as a predictive factor of SPTB without success. Several other inflammatory mediators (interleukins 6 and 8), possibly in combination, should be evaluated in these situations [35].

It is difficult to compare our results with the literature. Numerous biological mechanisms that vary between individuals may be implicated in the genesis of sPTB [36], and are poorly understood, despite significant research efforts [3, 30]. Systemic inflammatory response syndrome has been suggested as a diagnosis when no etiologic organism can be found, and infection accounted for up to $30 \%$ of cases of preterm labour may either be clinically-evident or sub-clinical. Then, this hypothesis of inflammation-infection in SPTB has been evaluated and inflammatory cytokines can be detected in elevated concentrations in the amniotic fluid and plasma of women with preterm labour [11, 19, 35]. Sorokin et al. demonstrated that an elevated maternal serum concentration of inflammatory biomarkers (interleukin 6 and CRP) are risk factors for PTB $<32$ weeks [35]. Only one study has evaluated serum PCT concentrations in patients with SPTB and intact membranes [19]. The study population consisted of 53 women with preterm labour and 31 healthy pregnant women. Serum PCT concentrations were significantly higher in patients with preterm labour compared to healthy pregnant patients (1.66 compared to $1.06 \mathrm{ng} / \mathrm{mL} ; p<0.05)$. Although at the onset of preterm labour serum PCT level in SPTB was higher that term birth, the difference was not significant [19]. No significant differences were also observed in PCT levels according to the admission-to-delivery interval. The authors concluded that the predictive value of serum PCT for patient admitted with TPL was unsatisfactory with poor predictive values for delivery within 36 weeks, 3 days or 7 days after admission [19].

\section{Conclusions}

Serum PCT was not relevant to predict sPTB within 7 or 14 days in women admitted with TPL, a singleton pregnancy, and intact membranes between 24 and 
36 weeks. These findings suggest that PCT is not the good biological marker to confirm the hypothesis of an inflammatory process associated with preterm parturition. Another study using several other inflammatory mediators (interleukin 6), possibly in combination, should be evaluated in these situations.

\author{
Abbreviations \\ CRP: C-reactive protein; NICU: Neonatal intensive care unit; \\ PCT: Procalcitonin; PPROM: Preterm premature rupture of membranes: \\ ROC: Receiver-operating curve; sPTB: Spontaneous preterm birth; \\ TPL: Threatened preterm labour; WBC: White blood cell
}

\section{Acknowledgements}

We would like to thank all the participants of the study and the supporting team of La Roche sur Yon Hospital who helped in data collection and patient management.

\section{Funding}

La Roche sur Yon Hospital provided the funding for the study. The funding source had no role in the study design, writing of the report, or the decision to submit the paper for publication.

\section{Availability of data and materials}

The datasets used and/or analysed during the current study are available from the corresponding author on reasonable request.

\section{Authors' contributions}

GD developed the original design. GD, JG and MV participated in the acquisition of the data. FDR realized the biological analysis. GD, ALT and JD analysed and interpreted the data. GD, ALT and JD performed the statistical analysis. GD wrote the first draft of the report. All authors contributed to the writing of the final manuscript. GD obtained funding and supervised the study. All authors have read and approved the final version of this manuscript.

\section{Ethics approval and consent to participate}

This study was conducted in accordance with the French approved guidelines. All participants underwent the informed consent process using institutional review board-approved consent documents; they were told about the study and were given written information at admission for TPL during pregnancy. Written consent was obtained by the medical team in charge of the study before inclusion. The study protocol and this consent procedure were approved by a Research Ethics Committee (CPP Ouest Rennes V, France) in October 2013 before inclusions (n² 2013-A01032-43). This trial is registered with clinicaltrials.gov (NCT01977079).

\section{Consent for publication}

Not applicable.

\section{Competing interests}

The authors declare that they have no competing interests.

\section{Publisher's Note}

Springer Nature remains neutral with regard to jurisdictional claims in published maps and institutional affiliations.

\section{Author details}

'Department of Obstetrics and Gynaecology, Centre Hospitalier Departemental, La Roche sur Yon, France. 'Department of Biology, Centre Hospitalier Departemental, La Roche sur Yon, France. ${ }^{3}$ Clinical Research Centre, Centre Hospitalier Departemental, La Roche sur Yon, France.

Received: 5 May 2017 Accepted: 1 March 2018

Published online: 07 March 2018

\section{References}

1. Lawn JE, Gravett MG, Nunes TM, Rubens CE, Stanton C, Group GR. Global report on preterm birth and stillbirth ( 1 of 7): definitions, description of the burden and opportunities to improve data. BMC Pregn Childbirth. 2010; 10(Suppl 1):S1.

2. Gyamfi-Bannerman C, Ananth CV. Trends in spontaneous and indicated preterm delivery among singleton gestations in the United States, 20052012. Obstet Gynecol. 2014;124:1069-74.

3. Frey HA, Klebanoff MA. The epidemiology, etiology, and costs of preterm birth. Semin Fetal Neonatal Med. 2016;21:68-73.

4. Han S, Crowther CA, Moore V. Magnesium maintenance therapy for preventing preterm birth after threatened preterm labour. Cochrane Database Syst Rev. 2013;5:CD000940.

5. World Health Organization; March of Dimes; The Partnership for Maternal NCHStC. Born too soon: the global action report on preterm birth. Geneva: World Health Organization; 2012.

6. Bennett TA, Kotelchuck M, Cox CE, Tucker MJ, Nadeau DA. Pregnancyassociated hospitalizations in the United States in 1991 and 1992: a comprehensive view of maternal morbidity. Am J Obstet Gynecol. 1998;178: 346-54.

7. Romero R, Erez O, Maymon E, Pacora P. Is an episode of suspected preterm labor that subsequently leads to a term delivery benign? Am J Obstet Gynecol. 2017;216:89-94.

8. Gazmararian JA, Petersen R, Jamieson DJ, et al. Hospitalizations during pregnancy among managed care enrollees. Obstet Gynecol. 2002;100:94-100.

9. MCPheeters ML, Miller WC, Hartmann KE, Savitz DA, Kaufman JS, Garrett JM, et al. The epidemiology of threatened preterm labor: a prospective cohort study. Am J Obstet Gynecol. 2005;192:1325-9. discussion 139-30

10. Ancel PY. Epidemiology of preterm births. Rev Prat. 2012;62:362-5.

11. Dudley DJ. Pre-term labor: an intra-uterine inflammatory response syndrome? J Reprod Immunol. 1997;36:93-109.

12. Gonzalez JM, Romero R, Girardi G. Comparison of the mechanisms responsible for cervical remodeling in preterm and term labor. J Reprod Immunol. 2013;97:112-9.

13. Romero R, Dey SK, Fisher SJ. Preterm labor: one syndrome, many causes. Science. 2014;345:760-5

14. Romero R, Espinoza J, Kusanovic JP, Gotsch F, Hassan S, Erez O, et al. The preterm parturition syndrome. BJOG. 2006;113:17-42

15. Assicot M, Gendrel D, Carsin H, Raymond J, Guilbaud J, Bohuon C. High serum procalcitonin concentrations in patients with sepsis and infection. Lancet. 1993:341:515-8.

16. Shaikh MM, Hermans LE, van Laar JM. Is serum procalcitonin measurement a useful addition to a rheumatologist's repertoire? A review of its diagnostic role in systemic inflammatory diseases and joint infections. Rheumatology. 2015;54:231-40.

17. Canpolat FE, Yiğit S, Korkmaz A, Yurdakök M, Tekinalp G. Procalcitonin versus CRP as an early indicator of fetal infection in preterm premature rupture of membranes. Turk J Pediatr. 2011:53:180-6.

18. Torbé A. Maternal plasma procalcitonin concentrations in pregnancy complicated by preterm premature rupture of membranes. Mediat Inflamm. 2007;2007:35782.

19. Torbé A, Czajka R. Maternal plasma procalcitonin concentrations in patients with preterm labor and intact membranes-prediction of preterm delivery and admission-to delivery interval. J Perinat Med. 2004;32:332-6.

20. Hadlock FP, Harrist RB, Sharman RS, Deter RL, Park SK. Estimation of fetal weight with the use of head, body, and femur measurements-a prospective study. Am J Obstet Gynecol. 1985;151:333-7.

21. French College of Gynecologists and Obstetricians. Intra-uterine growth retardation: guidelines for clinical practice - short text. J Gynecol Obstet Bio Reprod. 2013:42:1018-25.

22. Baud O, Emilie D, Pelletier E, Lacaze-Masmonteil T, Zupan V, Fernandez H, et al. Amniotic fluid concentrations of interleukin-1beta, interleukin- 6 and TNFalpha in chorioamnionitis before 32 weeks of gestation: histological associations and neonatal outcome. Br J Obstet Gynaecol. 1999;106:72-7.

23. Gibbs RS, Romero R, Hillier SL, Eschenbach DA, Sweet RL. A review of premature birth and subclinical infection. Am J Obstet Gynecol. 1992;166: $1515-28$

24. Sentilhes L, Sénat MV, Ancel PY, Azria E, Benoist G, Blanc J, et al. Prevention of spontaneous preterm birth: guidelines for clinical practice from the French College of Gynaecologists and Obstetricians (CNGOF). Eur J Obstet Gynecol Reprod Biol. 2017;210:217-24.

25. To MS, Skentou C, Chan C, Zagaliki A, Nicolaides KH. Cervical assessment at the routine 23-week scan: standardizing techniques. Ultrasound Obstet Gynecol. 2001;17:217-9. 
26. Kayem G, Maillard F, Popowski T, Haddad B, Sentilhes L. Uterine cervical length measurement by endovaginal ultrasonography: technique and main utilizations. J Gynecol Obstet Biol Reprod. 2010;39:267-75.

27. DeFranco EA, Lewis DF, Odibo AO. Improving the screening accuracy for preterm labor: is the combination of fetal fibronectin and cervical length in symptomatic patients a useful predictor of preterm birth? A systematic review. Am J Obstet Gynecol. 2013;208:233.e1-6.

28. Katz M, Goodyear K, Creasy RK. Early signs and symptoms of preterm labor. Am J Obstet Gynecol. 1990;162:1150-3.

29. Vayssière C, Vayssière C, Haumonte JB, Chantry A, Coatleven F, Debord MP, et al. Prolonged and post-term pregnancies: guidelines for clinical practice from the French College of Gynecologists and Obstetricians (CNGOF). Eur J Obstet Gynecol Reprod Biol. 2013;169:10-6.

30. Goldenberg RL, Culhane JF, lams JD, Romero R. Epidemiology and causes of preterm birth. Lancet. 2008:371:75-84.

31. lams JD, Goldenberg RL, Meis PJ, Mercer BM, Moawad A, Das A, et al. The length of the cervix and the risk of spontaneous premature delivery. National Institute of Child Health and Human Development maternal fetal medicine unit network. N Engl J Med. 1996;334:567-72.

32. Pinton A, Severac F, Meyer N, Akladios CY, Gaudineau A, Favre R, et al. A comparison of vaginal ultrasound and digital examination in predicting preterm delivery in women with threatened preterm labor: a cohort study. Acta Obstet Gynecol Scand. 2017;96:447-53.

33. Paccolat $\mathrm{C}$, Harbarth $\mathrm{S}$, Courvoisier D, Irion O, de Tejada BM. Procalcitonin levels during pregnancy, delivery and postpartum. J Perinat Med. 2011;39: 679-83.

34. Kucukgoz Gulec $U$, Tuncay Ozgunen F, Baris Guzel A, et al. An analysis of Creactive protein, procalcitonin, and D-dimer in pre-eclamptic patients. Am J Reprod Immunol. 2012;68:331-7.

35. Sorokin Y, Romero R, Mele L, Wapner RJ, lams JD, Dudley DJ, et al. Maternal serum interleukin-6, C-reactive protein, and matrix metalloproteinase-9 concentrations as risk factors for preterm birth $<32$ weeks and adverse neonatal outcomes. Am J Perinatol. 2010:27:631-40.

36. Moroz LA, Simhan HN. Rate of sonographic cervical shortening and biologic pathways of spontaneous preterm birth. Am J Obstet Gynecol. 2014;210: 555.e1-5.

\section{Submit your next manuscript to BioMed Central and we will help you at every step:}

- We accept pre-submission inquiries

- Our selector tool helps you to find the most relevant journal

- We provide round the clock customer support

- Convenient online submission

- Thorough peer review

- Inclusion in PubMed and all major indexing services

- Maximum visibility for your research

Submit your manuscript at www.biomedcentral.com/submit

) Biomed Central 